\section{RETHINKING BUSINESS \\ MODELS AS VALUE \\ CREATING SYSTEMS}

Professor Ted Fuller, Lincoln Business

School, University of Lincoln, Brayford

Pool, Lincoln, LN6 7TS; United King-

dom, Email: <tfuller@lincoln.ac.uk>

Dr Lorraine Warren, School of Management, University of Southampton, Highfield, Southampton, SO17 1BJ, United Kingdom.

Email: <l.warren@soton.ac.uk>

Sarah Thelwall, Arts Consultant <sarah@sarahthelwall.co.uk>

Fizza Alamdar, Lincoln Business School, University of Lincoln, Brayford Pool, Lincoln, LN6 7TS; United Kingdom. Email: <falamdar@lincoln.ac.uk>

Professor David Rae Lincoln Business School, University of Lincoln, Brayford Pool, Lincoln, LN6 7TS; United Kingdom. Email: <drae@lincoln.ac.uk>

\section{Abstract \\ The generic notion of a business model is well understood by investors and business managers and implies a number of anticipations; chiefly that it is a replicable process that produces revenues and prof- its. At its heart is some replicable process, artefact or proposition around which the everyday practices are formed. There are a number of reasons why this conception is weak in the Creative Industries. We have identified that the rationale for 'business mod- els' in the Creative Industries include providing an attractor for non goal oriented creative activity, for stabilising emergent properties from creative activi- ties and for maintaining the stability of these by anticipating revenues.}

\section{The Project}

This study within the overall CREATOR project was concerned with the puzzle that is inherent to creative domains; how to configure activities so as to generate income and to generate surplus income over costs. The current nomenclature for the way that an enterprise is configured such that its activities attract income in some way is the 'Business Model'. A business models is an organisation's core logic for creating value (Linder and Cantrell, 2000). This parlance can be seen as part of impersonalising enterprises. In a context where the purpose of business is to maximise profits, then the Business Model is an astringent and depersonalised 'machine', the repetitive action of which generates income and profits. A business model will be designed to maximise profits, with very little regard for other consequences of what is done. In the case of owner managed enterprises, the singularity of purpose is perhaps not so stark. In contexts where the main purpose of an enterprise is something other than maximising profits, then conceptions of 'business model' become confusing when seen from the profit maximisation perspective taken by some investors and some corporate managers.

Marketing theory is based on the exchange of value, and in business terms, the 'value proposition' that a business offers its 'customers' is what the customers will exchange their (typically) financial resources for. To have a successful business model, an enterprise will exchange one form of value with another form of value, typically a product, function or service that enables the purchaser to create value for themselves (do something better, save time, feel good etc.), exchanged with money. In this 'normal' model of business, the value proposition is readily constructed from extant capabilities and is normally repeatable. The business model is the process by which the exchange of value is enacted. It is normally a dyadic transaction between two parties, buyer and seller. However one aspect of the wired world is that greater interconnections result in a network of value exchange, such that the simple dyadic measures of value exchange do not account for the total value produced and exchanged by the system.

The dyadic mode of conceptualising value and value exchange creates significant limitations when attempting to understand processes of value exchange in the creative sector. It does not capture the range of values that are important in the creative industries, nor the need to capture value across distributed innovation networks. The digital challenges to the industry that are rendering past notions of business obsolete include user generated content, free reproduction and distribution, innovations in the process of engagement and new ways of monetising this world, eg creative commons.

Hearn et al (2007) suggest that it would be unwise to adopt uncritically models derived from other industry sectors without considering the particular dynamic of the creative industries. They argue for 'value creating ecologies', where value creation is not a readily understood one-way process, as implied by the value chain, but instead involves systemic processes of reiteration, feedback and co-creation on the part of consumers as well as producers, where the lines between production and consump- tion are increasingly blurred. Shift in the conceptualization of value creation in business, termed as emergence of value ecology thinking (Hearn and Pace 2006).

These shifts are from thinking about

- Consumers to co creators of value

- Value chains to value networks

- Product value to network value

- Simple co-operation or competition to complex co-opetition and

- Individual firm strategy to strategy in relation to value ecologies

We found Chesbrough's distinction between value creation and value capture to be a helpful analytical difference when considering some of the cases we looked at in the Creator project. The Business Model performs two important functions [2, p2]: "it creates value and it captures a portion of that value. It creates value by defining a series of activities from raw materials through to the final consumer that will yield a new product or service with value being added throughout the various activities. The business model captures value by establishing a unique resource, asset or position within that series of activities, where the firm enjoys a competitive advantage".

Our previous work on emergence in entrepreneurial contexts, i.e. what is produced from entrepreneurial activities and how, leads us to consider that business models are themselves emergent and evolutionary. We have identified processes that appear to shape the evolution of a particular business model (EROS) (e.g. [3, 4] . Informed by Sawyer's 'Emergence Paradigm' [5] of social structures, we identify that interactions produce ephemeral emergents, which have a causal effect on the evolution of the enterprise. It seems to us that processes which produce ephemeral emergents are value creating, whereas processes that stabilise the emergent properties are value capturing.

For artists, as Thelwall [6] argues, in a cultural context, value may not be primarily acknowledged through the economics of the marketplace; indeed value may be conceived through sophisticated social understandings of reputation, peer recognition, audience reach and aesthetic and conceptual quality. Thelwall suggests that artists and cultural organisations may be well aware of untapped economic potential in their practice, but shy away from realising them, perhaps because of a pervasive myth that commercial and cultural success are somehow mutually exclusive. 
This suggests that the main purpose and motivation of artists is value creation (not capture). And the meaning of 'value' is idiosyncratic: its definition depends on the milieu in which it is situated. It is what is taken for value within that set of interconnections that guides and shapes the performance of the creative person, be they artist or programmer. What emerges from a valuecreating model is existential value in its context. Such a model does not 'capture' value; it produces or creates the potential for value capture. This potential, and perhaps the emergent properties (ie what is produced, such as emergent structures or 'emergents') of the creative activity, is ephemeral; it exists but its trace may disappear. What drives the value creation process is the anticipation of inherent value or reputational benefits for the creator, i.e., that their individual or collective efforts are recognised by their salient community (made salient by a resonant value system). Such recognition may include financial rewards, such as public grants.

A value capture model is one we argue, in which explicit rewards are anticipated; typically financial rewards. Such models are more de-personalised, though not entirely, as reputation provides value. In order to be part of a value capturing system, the created emergent properties need to become stabilised. The anticipation of their future captured value is the motivation for their stabilisation. For as long as this anticipation exists, the emergents are stabilised.

They may of course be modified in small ways as the anticipation changes. Typically such stabilisation comes through codification, e.g. as a contract to perform or exchange, extant intellectual property rights, cloning kits, value propositions, artefacts etc.

\section{Case studies}

We looked specifically at two case studies of enterprises that appear to be situated in creative ecologies; networks of creative people and activities and consumers of the created. In both cases they appeared to act in multiple roles; referring to themselves as being in a mixed economy of financial models and creative.
iShed is a Community Interest Company (ie has a legally registered form) acting as a broker. iShed team spots or selects individuals or companies to support them in exploring creative potential of new technologies. These individuals or companies do not have fund nor platform themselves to engage in such an activity. Funding is then sought by iShed for supporting such a project. Their financing comes from public and private sector, with Hewlett Packard being a significant sponsor, making emerging technologies available for creative people to use, in the expectation that some exploitable benefit will arise from this process. The 'value capturing' structure of $\mathrm{HP}$ and the value creating structures of the iShed networks are linked by the multiple activities of iShed.

SCAN is an agency developing media arts set up as a platform for collaboration and sharing of resources between 12 consortium members in Southern UK. SCAN works in partnership with a various individuals, groups and institutions on national and international level to commission innovative projects that combine disciplines from arts, media, humanities, science and technology. It explores ideas, sites and tools showing the creative potential that media arts offer. SCAN works extensively within the higher education sector on research projects, realising public outputs and outcomes from research and brokering partnerships. It is mainly financed by public funds and has to demonstrate that it is creating equivalent value from its activity from attracting in-kind resources and non financial valued outcomes (as they say, a stimulator as well as an energy attractor).

\section{Creating and stabilising emer- gent properties}

In their own ways, both of these enterprises have, as a basic logic, the creation of linkages between value creation and value capture systems or ecologies. They provide closure to structural holes between two systems or ecologies that have different values and motives. They provide a structuring function, or attractor to a value creating ecology whose main motive is non-financial value creation.
They also have a capability to stabilise the ephemeral emergents sufficiently to introduce these into value capturing ecologies, ie the market.

The analysis of these cases to date is incomplete but it suggests that three types of business model are necessary for creative people and activities to produce financial value in a reproducible form. The first is a model that creates the conditions for creativity and reputation by establishing attractors; typically resources for co-operation. The second is a model that stabilises the emergent properties of the first; typically the creation of codified knowledge. The third is one that enables the exchange of monetary value for this codified knowledge, and is more recognisable as a business model by investors

\section{Acknowledgement}

This project is part of the EPSRC cluster project, http://www.creatorproject.org/, (EP/G002088/1)

\section{References and Notes}

1. Tapscott, D. and A.D. Williams, Wikinomics : how mass collaboration changes everything. 2006, New York, N.Y.: Portfolio ; London : Penguin.

2. Chesbrough, H.W., W. Vanhaverbeke, and J. West, Open innovation : researching a new paradigm. 2006, Oxford: Oxford University Press.

3. Fuller, T., L. Warren, and P. Argyle, Sustaining entrepreneurial business: A complexity perspective on processes that produce emergent practice. The International Entrepreneurship and Management Journal, 2008. 4(1): p. 1-17.

4. Fuller, T. and L. Warren, Entrepreneurship as foresight: A complex social network perspective on organisational foresight. Futures, Journal of Policy, Planning and Futures Studies, 2006. 38(8).

5. Sawyer, R.K., Social Emergence: Societies As Complex Systems. 2005, Cambridge: Cambridge University Press.

6. Thelwall, S., Capitalising Creativity Developing earned income streams in Cultural Industries organisations, in Cultural Snapshot. 2007. 